\title{
Cold Sprayed Tungsten Armor for Tokamak First Wall
}

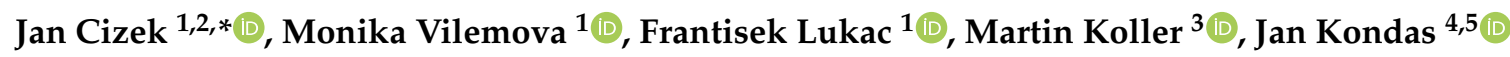 \\ and Reeti Singh ${ }^{4}$ \\ 1 Institute of Plasma Physics, The Czech Academy of Sciences, 18200 Prague, Czech Republic; \\ vilemova@ipp.cas.cz (M.V.); lukac@ipp.cas.cz (F.L.) \\ 2 Institute of Materials Science and Engineering, Brno University of Technology, 61669 Brno, Czech Republic \\ 3 Institute of Thermomechanics, The Czech Academy of Sciences, 18200 Prague, Czech Republic; \\ koller@it.cas.cz \\ 4 Impact Innovations GmbH, 84431 Rattenkirchen, Germany; jk@impact-innovations.com (J.K.); \\ rs@impact-innovations.com (R.S.) \\ 5 Department of Mechanical Engineering, Politecnico di Milano, 20156 Milan, Italy \\ * Correspondence: cizek@ipp.cas.cz; Tel.: +420-266-052-096
}

Received: 9 September 2019; Accepted: 2 December 2019; Published: 7 December 2019

\begin{abstract}
Harnessing nuclear fusion is a challenging task, in particular because of the demands put on the used materials. In tokamaks, future energy sources, the inner-most chambers are to be coated with dense coatings of W, or W-Cr-based alloys. So far, the attempts for such coatings formation by other methods failed due to oxidation, high porosity, insufficient adhesion, high specific surface, or even insufficient thickness below $10 \mu \mathrm{m}$. Cold spraying seems a promising technology for the task. In our study, we demonstrate the first successful fabrication of thick pure W coatings. W-Cr and $\mathrm{W}$-Cr-Ti coatings were further prepared without oxidation of the metals. All coatings exhibited high hardness levels, good interface quality with three tested substrates and, importantly, a promising potential for formation of stable $\mathrm{Cr}_{2} \mathrm{WO}_{x}$ phases.
\end{abstract}

Keywords: cold gas kinetic spray; $\mathrm{W}-\mathrm{Cr} ; \mathrm{W}$ alloys; oxidation shield; nuclear fusion; thick coatings; self-passivation; PFC; plasma facing components

\section{Introduction}

Nuclear fusion is a process in which two or more light atomic nuclei combine to form a different, heavier nucleus and subatomic particles, neutrons or protons. Due to the difference in the binding energy of the nuclei, a significant amount of energy is released in the reaction (an amount surpassing even that of nuclear fission). The reaction that is currently considered the most promising for future power production is fusion of two hydrogen isotopes, deuterium (D) and tritium (T):

$$
\mathrm{D}+\mathrm{T} \longrightarrow{ }_{2}^{4} \mathrm{He}+{ }_{0}^{1} \mathrm{n} \text {. }
$$

Combining these leads to formation of helium atoms carrying $3.5 \mathrm{MeV}$ energy used to further heat the fuel, and free neutrons having energies of $14.1 \mathrm{MeV}$. This energy is used for breeding of tritium as well as the energy production. In order to achieve positive energy balance, it is necessary to ensure a sufficient frequency of these reactions (collisions of $\mathrm{D}$ and $\mathrm{T}$ ). This translates into the requirement to keep the fuel at sufficiently high temperatures and concentrations for sufficiently long times [1-3]. Meeting these criteria, tokamaks are torus-shaped fusion facilities where the plasma is confined using magnetic fields. They represent an inherently safe and relatively cheap energy technology (considering the abundance of fuel) that produces radioactive waste with relatively short half-life. An illustration of a tokamak vessel is provided in Figure 1. 


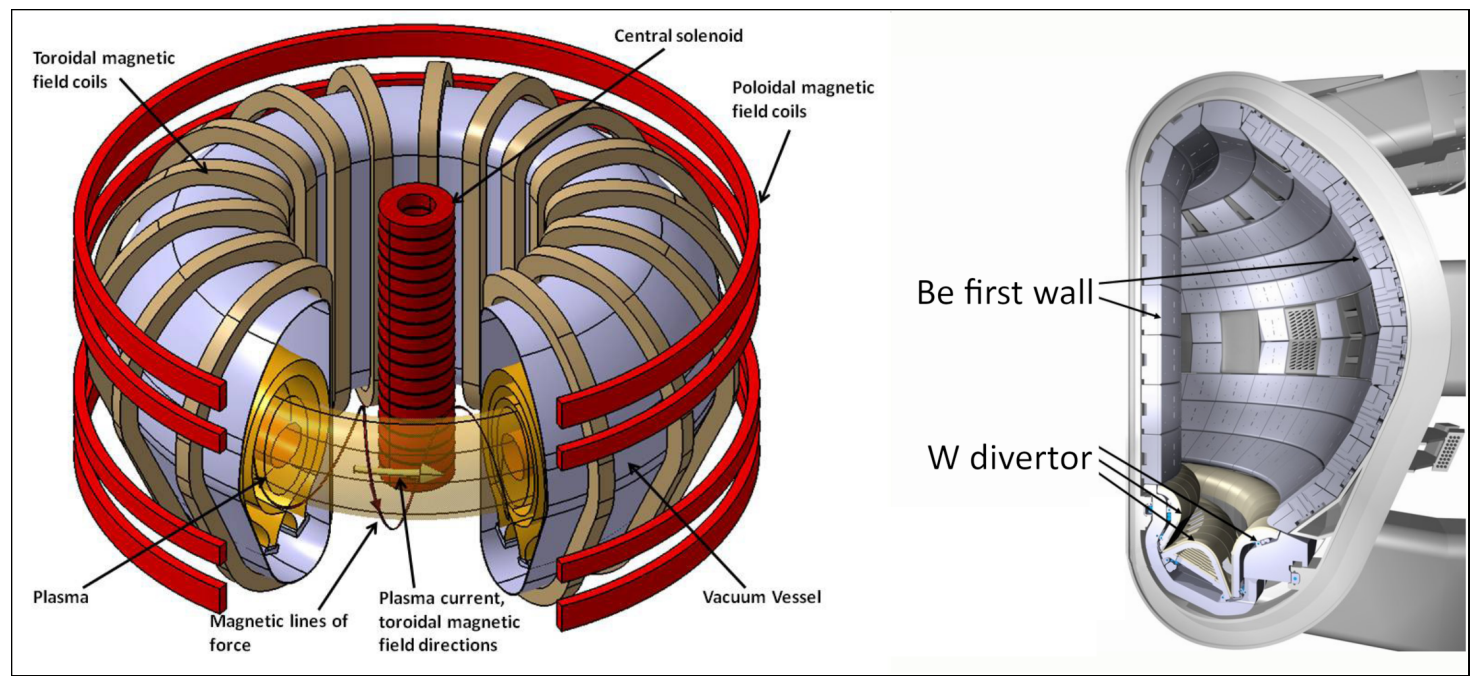

Figure 1. (Left) Schematic of a tokamak fusion reactor [4]. (Right) Cross section of ITER vacuum vessel and the plasma facing components (courtesy of ITER).

In these reactors, the materials will be subjected to extreme thermo-mechanical or radiation conditions and required to sustain functionality for prolonged periods of time. To get a basic insight, the plasma housed in the tokamaks could reach temperatures up to $10^{8}{ }^{\circ} \mathrm{C}$ due to its density and amount of stored energy. Despite the plasma being confined by the strong magnetic fields preventing a direct contact, the selection of refractory materials for the so called plasma-facing components (PFCs, [1,2]) presents one of the major challenges in the surface engineering of the components used for construction of the tokamak vessel. In the recent years, the studied materials for the PFC armor included variations of graphite (mostly in a form of carbon-reinforced carbon) or beryllium (later rejected due to its toxicity), while low-activation steels such as EUROFER were used for the PFC structural frame.

Tungsten and its alloys have many favorable properties, such as high melting point $\left(T_{m}=3422{ }^{\circ} \mathrm{C}\right.$ for pure $\mathrm{W}$ ), thermal conductivity superior to the structural steels, low erosion (i.e., high energy threshold to suffer from sputtering) as well as low tritium retention. Understandably, pure tungsten is therefore intended to be applied in the lower part of the reactor vessel, so called divertor region (Figure 1 shows such solution for the tokamak ITER), while tungsten alloys are planned for the remaining surfaces of the so called first wall. Unfortunately, the processing of PFCs is complicated by tungsten's inherent brittleness (high ductile-to-brittle transition temperature), poor weldability and machinability, thermal expansion coefficient mismatch with the structural steels, or susceptibility to grain growth and to oxidation above $500{ }^{\circ} \mathrm{C}$.

At normal vessel operation, the latter factor should not present an issue as the entire system is vacuum tight. However, bearing in mind the safety aspects, an extensive oxidation triggering formation of volatile oxides would present a major threat in case of an accident such as loss of coolant and simultaneous air ingress into the reactor vessel. Interaction of oxygen with tungsten at high temperatures leads to formation of $\mathrm{WO}_{3}$ that is highly volatile. During reactor operation, the tungsten will be activated by the high energy neutrons and thus, without any risk mitigation, large amounts of radioactive $\mathrm{WO}_{3}$ might be dispersed into the surrounding. Such safety concerns led to development of self-passivation tungsten alloys via addition of various oxide-forming elements, triggering a formation of protective oxide scale upon exposure to air. For instance, significant improvement of oxidation behavior have been achieved with W-Cr-Y and W-Cr-Ti systems $[5,6]$.

Ideally, the chromium content should be evenly distributed throughout the tungsten matrix in a form of a solid solution. This is, however, complicated due to the miscibility gap limiting the maximum chromium concentration in the solid solution (Figure 2). Another complication is the fact that fabrication of pure $\mathrm{W}$ and $\mathrm{W}-\mathrm{Cr}$ bulk alloys via traditional metallurgy routes is very difficult. 
Aside from the economic aspects (mind the very high melting temperatures), the reactivity of both metals with oxygen presents a major problem, as well as the fact the the melting point of $\mathrm{W}$ is above the boiling point of $\mathrm{Cr}\left(2672^{\circ} \mathrm{C}\right)$. Given that, the research focus is shifting toward the potential of surface engineering methods/manufacturing techniques. This field is largely unexplored and a lot of effort will be needed to provide perfect armor coatings for the W-based components. At the moment, there is a critical need for a robust, simple and cost-effective technology that would ideally sidetrack the need for welding. Cold spray is one such technology. It is a commercially available, high-throughput, large-scale and versatile process capable of fabricating protective coatings directly onto structural parts. This presents yet another potential advantage as the armor coatings could be produced directly onto the first wall surface, without a need for second technological step such as joining or welding. Importantly, cold spray is a single-step technology that does not require (except for final surface machining) any subsequent technological procedures such as heat treatment. As noted by Pintsuk [2], the tungsten compacts furnace-sintered from powders at $2500{ }^{\circ} \mathrm{C}$ still possess $80 \%$ of the bulk density. Again, this is resolved by cold spraying as the method allows pore-free coating formation (a significant improvement over e.g., plasma spraying).

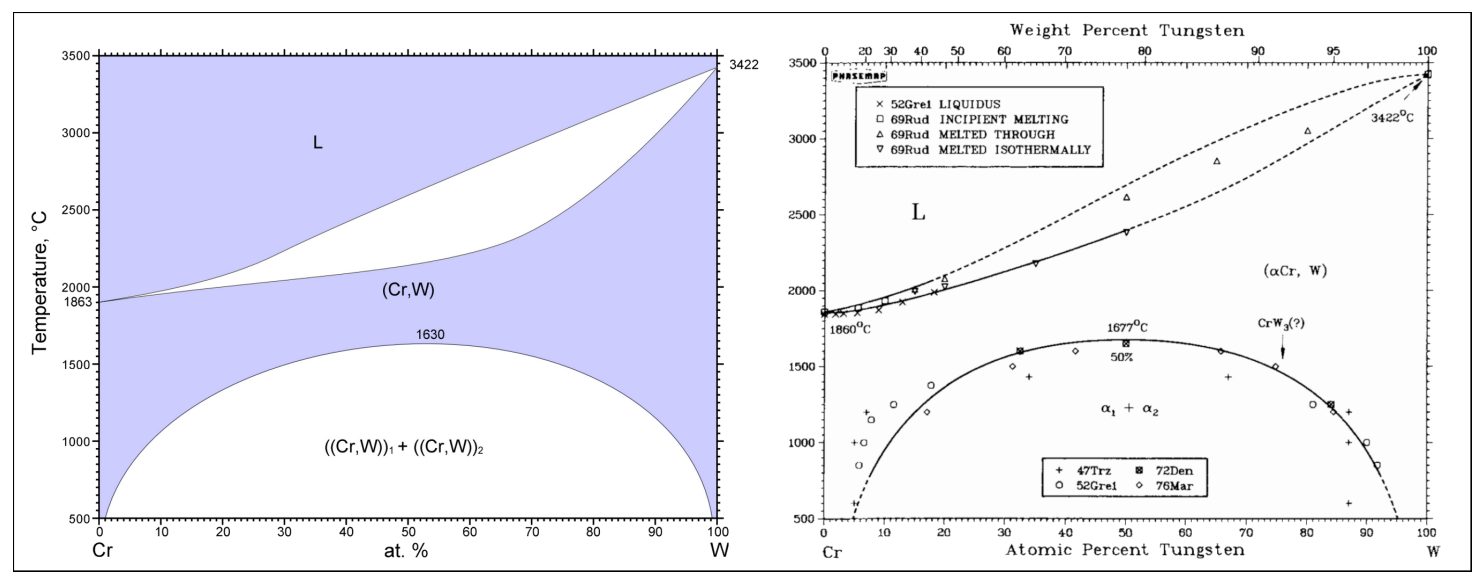

Figure 2. Binary phase diagram of W-Cr showing miscibility gap and limited chromium concentration in the W-based solid solution at room temperature. (Left) Calculated diagram reproduced from ASM International binary phase diagram collection database 2017. (Right) measured diagram from Naidu et al. [7].

Using kinetic energy in lieu of thermal input, the method is particularly suitable for deposition of metals $[8,9]$. As opposed to thermal spray processes such as plasma spray or HVOF, the temperatures involved in this process remain relatively low, thereby effectively eliminating oxidation of the materials. In cold spray, the metallic particles are accelerated to high velocities and adhere to the underlying material by means of extensive plastic deformation upon impact. By subsequent movement of the torch over the prepared surface, a coating is formed.

Cold spraying of tungsten is a challenging task. Up to date, no pure $\mathrm{W}$ thick coating was successfully fabricated, with some of the results showing a one-layer structure formed owing to the relative substrate softness (embedded particles). As a workaround, mixing of the tungsten phase with other, more malleable and ductile elements can be used. This is frequently combined with enhancing the coating properties by a targeted selection of the ductile matrix that contributes to the desired application properties. Even then, the studies employing such concept are limited in the literature and involve successful depositions of W-Cu by Kang and Kang [10] and Deng et al. [11], W-Ni-Fe by Xia et al. [12], and low tungsten content in W-90Ta coatings by Barnett et al. [13] only. Considering their excellent wear properties, a significantly broader series of studies involved the research of cemented carbides in a form of WC-Co [14-31], WC-Ni [32-41], WC-Co-Ni [42], WC-Co-Cr [31,43-45], or WC-Cu-MoS $2[46,47]$. Unfortunately, the carbides could not be used for PFCs and so we could not built on these results. 
Considering the limited outputs on W-based materials processed by cold spray and the fact that cold spray technology is apparently rather unfamiliar to the nuclear fusion sector, the focal point of the presented study is to prove that pure $\mathrm{W}$ and $\mathrm{W}$-based coatings can be produced by the technology, with high quality ensuring a potential application in nuclear fusion industry.

\section{Experimental Setup}

\subsection{Materials}

In order to aid in our understanding of the process, three different commercially available tungsten powders were used in the study. Their respective particle size ranges were classified into $20-28 \mu \mathrm{m}, 10-15 \mu \mathrm{m},+20 \mu \mathrm{m}$. The chemical purity of the powders was indicated as $99.95 \%$. The used $-30 \mu \mathrm{m}$ flaky chromium powder was fabricated via pulverization method (US Research Nanomaterials, Houston, USA) with purity indicated as $99.5 \%$. Lastly, plasma atomized titanium powder of the sieve range $15-45 \mu \mathrm{m}$ and $99.5 \%$ purity was used in some combinations (Advanced Powders \& Coatings Inc., Boisbriand, Canada).

Taking advantage of powder metallurgy routes, six different series of feedstock were prepared from the primary powders, as listed in Table 1. Pure W (for coating A), to manifest that thick W coatings can be deposited by cold spray technology at its current state-of-the-art. Further, a blend of $\mathrm{W}$ and $10 \% \mathrm{Cr}$ (coatings B, C; weight percentages are used throughout this paper) was prepared, a combination that could be of interest to fusion science owing to its oxidation behavior. Thirdly, blends of $\mathrm{W}$ and 5\% Ti (coating D) and $\mathrm{W}$ and 10\% $\mathrm{Cr}$ and 5\% Ti (coating E) were produced to observe the improvement in the coating build-up and density by exploiting the ductile binder phase phenomenon in cold spray. The last coating (F) was produced by mechanically alloying of $\mathrm{W}$ and $12 \%$ Cr powders (Pulverisette 5 premium line, Fritsch, Idar-Oberstein, Germany), after which 5\% Ti was blended into the mixture. In the milling, a WC-based milling jar and balls were used with the ball-to-powder ratio of 3.5:1. Protective argon atmosphere was used. The milling parameters were set as $100 \mathrm{rpm}$ and $15 \mathrm{~h}$. The milling process was then interrupted and resumed for another $25 \mathrm{~h}$ at $120 \mathrm{rpm}$. The final feedstock morphologies are shown in Figure 3, along with a cross-section microstructure of the milled powder used for coating $\mathrm{F}$. In this powder, the $\mathrm{W}$ and $\mathrm{Cr}$ content formed layered alternating lamellae, i.e., the powder offered an extended mutual contact interface between the two metals. Due to the dissimilar densities of the constituents, the blending process of each blend B-F was carried out for at least four hours using a horizontal jar mill. The powders were not heated prior to deposition.

Table 1. Six different W-based feedstock materials cold sprayed in this study. Note that three different substrates were used in order to assess the influence of the materials' relative hardness.

\begin{tabular}{cccccc}
\hline \multirow{2}{*}{ Coating Annotation } & \multicolumn{3}{c}{ Content (wt.\%) } & \multirow{2}{*}{ Substrate } & \multirow{2}{*}{ Feedstock Preparation } \\
& W & Cr & Ti & & \\
\hline A & 100 & & & Al 6060 & \\
B & 90 & 10 & & Al 6060 & mechanically blended \\
C & 90 & 10 & & Steel 1.1191 & mechanically blended \\
D & 95 & & 5 & AISI 304 & mechanically blended \\
E & 85 & 10 & 5 & AISI 304 & mechanically blended \\
F & 83 & 12 & 5 & AISI 304 & W+Cr milled, Ti blended \\
\hline
\end{tabular}

To tackle the phenomenon of difficulty of thick $W$ coatings formation (discussed in studies [10-12]), three different substrate materials were used. These included a relatively soft Al 6060 alloy (62 HV1), medium-hardness stainless steel AISI 304 (232 HV1), and relatively hard steel 1.1191 (ferrite-pearlite steel with $0.42-0.5 \%$ C, 278 HV1). Considering the hardness differences, the interface observations will aid in our understanding of the W-based coating formation process. 

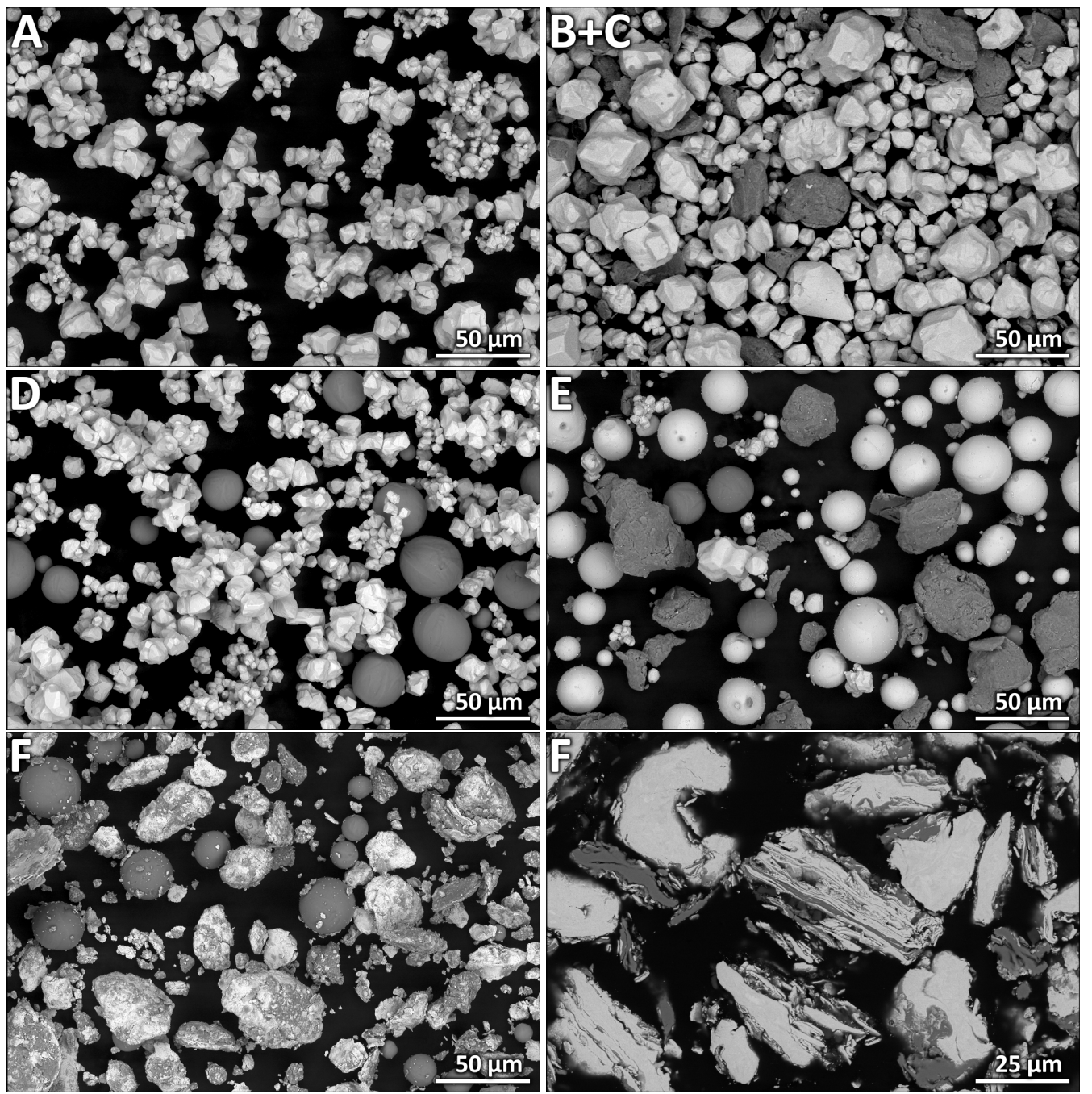

Figure 3. Morphologies of the powder blends used in this study. The annotation corresponds to the coating annotation presented in Table 1 and Figure 4. The last image shows internal (cross-section) microstructure of the milled powder used for coating F, illustrating the layered character of the particles.

\subsection{Cold Spray Deposition}

Prior to deposition, KSS software (version 1.4.0, Kinetic spray solutions, Buchholz in der Nordheide, Germany) was used to simulate the spray conditions and obtain the parameters required to deposit the $\mathrm{W}$ coatings. Given the average particles sizes of the used $\mathrm{W}$ powders and the geometry of the used torch nozzle, average particle velocities of $v_{p}=601 \mathrm{~m} \cdot \mathrm{s}^{-1}$ were achievable. In turn, this triggered the need to use very high spray parameters.

The deposition was therefore realized using a high-pressure system 5/11 from Impact Innovations $\mathrm{GmbH}$ (Rattenkirchen, Germany). The torch is capable of achieving the pressures of 5.0 MPa and temperatures of $1100{ }^{\circ} \mathrm{C}$ of the nitrogen main process gas. Fine-tuning of the spray parameters for the pure $\mathrm{W}$, or blended or mechanically alloyed (metallurgically bonded) feedstock was realized. Aside from the $\mathrm{W}$-based combinations (B-F), the high torch parameters showed to be crucial in the deposition of pure $W$ (coating A). The in-flight particle velocity of pure $W$ reached $780 \mathrm{~m} \cdot \mathrm{s}^{-1}$ (an average measured from 1000 particles).

The AISI 304 steel substrates were grit-blasted prior to deposition. An area of $30 \times 20 \mathrm{~mm}^{2}$ was sprayed on the 1.1191 steel, an area of $40 \times 30 \mathrm{~mm}^{2}$ on the AISI 304 and an extended area of $80 \times 300 \mathrm{~mm}^{2}$ on the $\mathrm{Al} 6060$ substrates. No secondary treatment of the samples (e.g., heat-treatment or HIP consolidation) was carried out after the deposition. 


\subsection{Coatings Characterization}

Given the rather dissimilar properties of the used materials, a specific methodology was used for the preparation of metallographic samples. After the grinding and polishing using $1 \mu \mathrm{m}$ diamond paste, the samples were further processed in OPS (colloidal silica) for extended times of $24 \mathrm{~h}$ in vibratory polisher (Vibromet 2, Buehler, Lake Bluff, USA).

The cross-section specimens were then used for SEM imaging (Evo MA 15, Zeiss, Oberkochen, Germany) realized in back-scattered electron (i.e., atomic number sensitive) mode at short work distances 6-8 mm. EDX analyses and mapping were realized using Quantax SDD XFlash 5010 detector (Bruker, Billerica, USA). Phase composition was determined by Rietveld refinement of the acquired XRD spectra (D8 Discover, Bruker) equipped with 1D LynxEye detector. Hardness of the materials was measured at $100 \mathrm{gf}$ and $300 \mathrm{gf}$ (coatings) and $1000 \mathrm{gf}$ (substrates) load and dwell times of $10 \mathrm{~s}$ using Q10A+ universal hardness tester (Qness, Golling an der Salzach, Austria). At least 12 valid measurements were included in calculation of the average.

Elastic properties of the coatings were further determined by measuring ultrasonic waves velocities by through-transmission method [48]. For each coating, a $\sim 300 \mu \mathrm{m}$ thick sample was cut so that the thickness of the sample was parallel to the spraying axis. Individually, the samples were then inserted between two longitudinal wave ultrasonic transducers (Ultran DCB25-10 with $10 \mathrm{MHz}$ nominal frequency) and the velocities of quasi-longitudinal waves $v_{q L}$ were obtained by measuring times of flight of the ultrasonic waves propagating through the samples. Similarly, transverse waves transducers (Ultran SRD25-2 with $2 \mathrm{MHz}$ nominal frequency) were used to measure the velocities of quasi-transverse waves $v_{q T}$. The elastic coefficients of $c_{11}$ and $c_{44}$ were determined as

$$
\begin{aligned}
& c_{11}=\rho v_{q L}^{2} \\
& c_{44}=\rho v_{q T}^{2},
\end{aligned}
$$

where $\rho$ is the density of the coatings [49]. Moreover, Young's moduli $E$ and Poisson's ratios $v$ were calculated from these values, utilizing the standard conversion formulae for elastic moduli [50].

The propensity of the coatings to oxidation was evaluated by exposing the coatings to air atmosphere at $1000{ }^{\circ} \mathrm{C}$. For these, samples with the base of $5 \times 5 \mathrm{~mm}^{2}$ were cut. To study the development at the interface, the substrates were not removed from these. No surface polishing was applied. The experiments were performed in a high temperature furnace using synthetic air $\left(20.9 \% \mathrm{O}_{2}, 78.8 \% \mathrm{~N}_{2}, 3 \mathrm{ppm} \mathrm{H}_{2} \mathrm{O}\right)$. The heating rate to the final oxidation temperature was $5{ }^{\circ} \mathrm{C} \cdot \mathrm{min}^{-1}$ and the hold time at the oxidation temperature was $10 \mathrm{~h}$. A subsequent cooling to $700{ }^{\circ} \mathrm{C}$ was then conducted at a controlled rate of $5{ }^{\circ} \mathrm{C} \cdot \mathrm{min}^{-1}$, followed by free cooling to room temperature. Such conditions are somewhat more severe as compared to those the materials will be subjected to during steady state operation conditions $\left(500-600{ }^{\circ} \mathrm{C}\right)$. However, their selection was made to simulate the case of LOCA (loss of coolant accident) where the temperatures could increase to $1000-1200{ }^{\circ} \mathrm{C}$ due to radioactive decay. As the most important information for any future coating optimization is the prospective formation of non-volatile oxides stable above $1000{ }^{\circ} \mathrm{C}, \mathrm{XRD}$ was selected as the evaluation tool, with the obtained spectra processed by Rietveld analysis [51] for quantification of the oxidation products. In these test, the latter coatings D-F containing 5\% Ti were used only. The selection is based on the fact that these coatings exhibited a significantly higher deposition efficiency, a rather critical condition considering the intended application of the technology for the large-scale first wall in tokamaks.

\section{Results and Discussion}

The microstructure of the fabricated cold sprayed coatings can be seen from Figure 4 . The pure $\mathrm{W}$ coating reached average thickness $78 \mu \mathrm{m}$ and appeared dense along its entire length. The tungsten particles embedded into the relatively soft $\mathrm{Al} 6060$ substrate were less deformed as compared to the particles deposited by the subsequent torch passes. Demonstration of such tamping effect [52-54] 
is a consequence of decreasing deposition efficiency, as shown by Xie et al. [55]. The W-10Cr coatings $B$ and $C$ exhibited similar tamping phenomenon towards the free surface, with the coating $\mathrm{C}$ experiencing higher overall level of particles spreading. This could have been triggered by two factors: deposition onto harder steel substrate and repeated delamination of portions of the coatings upon the spraying (evidenced by surface view SEM examination), exposing the previously deposited material to further particle impingement. The thickness of coatings B and C exceeded $200 \mu \mathrm{m}$ and, importantly, the chromium content in both coatings was distributed evenly. In both cases, however, the overall deposition efficiency was rather low (this could be improved in the near future as first studies on a successful deposition of Cr were presented recently [56]) and the mutual cohesion of the particles was not flawless as cracks spanning several particles were observed in the microstructures. This led to the idea of adding a binder material to the blends. Considering the half-lives and ease of sprayability, and taking into account the fact that it had been used in self-passivation alloys previously [57-59], titanium was selected as the prime candidate over $\mathrm{Al}, \mathrm{Ni}$, or $\mathrm{Cu}$.

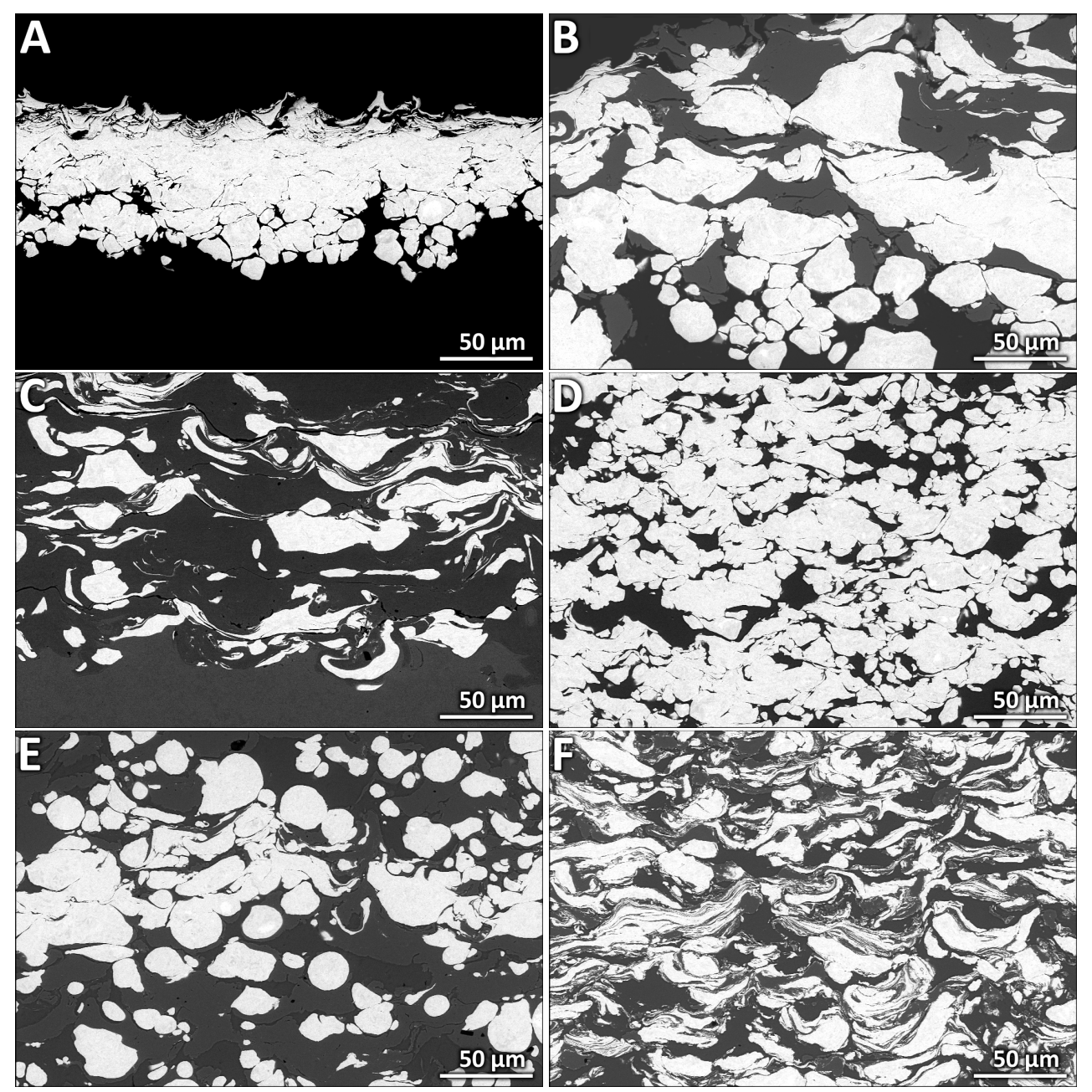

Figure 4. Microstructure of the produced cold spray coatings A-F The bright phase is tungsten. In coatings $\mathrm{B}, \mathrm{C}$, the dark phase is chromium, in coating D titanium. In coatings $\mathrm{E}, \mathrm{F}$, titanium is darker than chromium; see the EDX mapping of the two coatings in Figure 5 for more magnified view.

The coatings containing 5\% titanium exhibited significantly improved, crack-free microstructure. The principle exploited here is the ductile binder aiding in the adherence of incoming tungsten (and chromium) particles, as in the studies [10-13]. The coatings easily reached thicknesses from 450-1100 $\mu \mathrm{m}$ and experienced no troubles with deposition efficiency. The tamping effect observed for coatings A-C was not manifested. Again, the chromium and titanium contents were distributed evenly 
throughout the entire thickness and, in the case of coatings $\mathrm{D}$ and $\mathrm{E}$, prevented excessive deformation of the $\mathrm{W}$ particles. The effect of mechanical alloying of the $\mathrm{W}$ and $\mathrm{Cr}$ powders in coating $\mathrm{F}$ can be nicely seen in comparison with the mixed-only blend of coating $\mathrm{E}$ (Figure 5). The individual $\mathrm{W}$ particles were in fact layered alternating lamellae of $\mathrm{W}$ and $\mathrm{Cr}$, a microstructure inherited from the feedstock powder. Such finer microstructure of the particles could contribute to oxidation resistance of the coatings by shortening the diffusion path of oxide scale forming elements. The microstructure of coatings $\mathrm{E}$ and $\mathrm{F}$ seems very promising towards formation of chromium-based oxides.
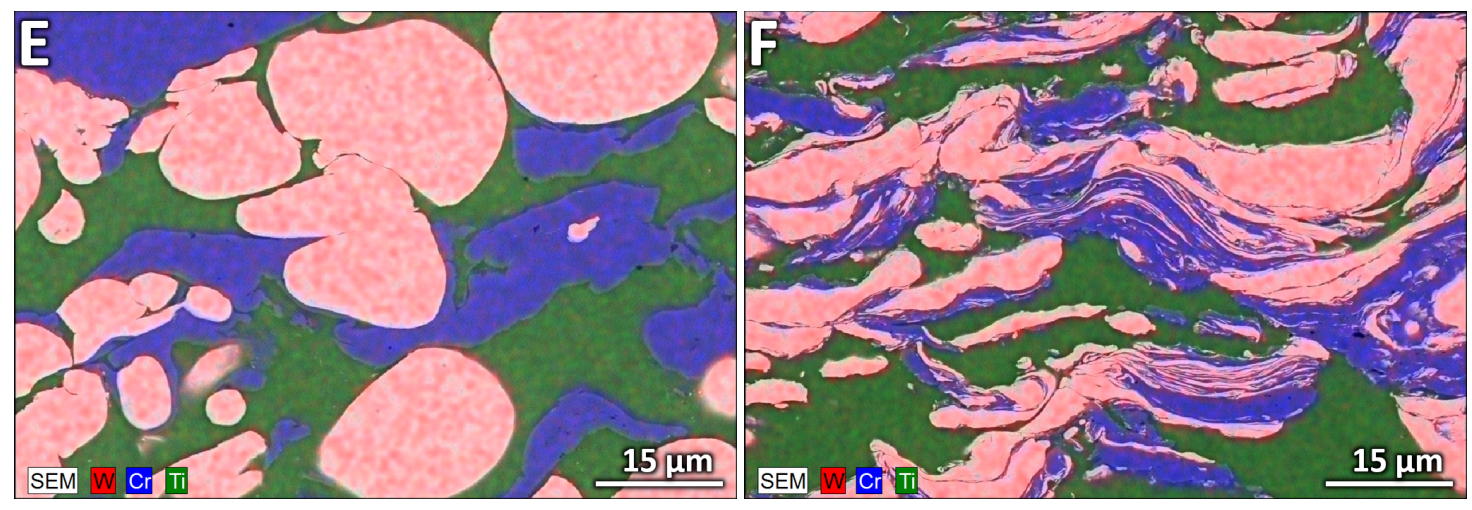

Figure 5. Enhanced elemental maps of the produced cold spray coatings E and F. Note the difference between blended-only $\mathrm{W}$ and $\mathrm{Cr}$ particles in coating $\mathrm{E}$ and the lamellar structure of the co-milled $\mathrm{W}$ and $\mathrm{Cr}$ particles in coating $\mathrm{F}$.

The interface quality of the six produced coatings is shown in Figure 6. Non-deformed (slightly deformed) particles could be clearly seen at the interface of coatings A and B and the Al 6060 alloy substrate. Preservation of the original morphology of the particles is due to the embedding phenomenon commonly encountered in cold spraying onto soft substrates. Contrary to this, the coating $C$ deposited onto relatively hard steel 1.1191 exhibits a significant ratio of particle flattening directly at the interface already. Somewhat in between these in terms of plastic deformation of the first layer of particles are coatings D-F deposited onto medium hardness AISI 304 steel (note that the deformation of particles in coating F stems from the powder milling process). Overall, the interface quality of all coatings is very good, with only minor imperfections observed infrequently. This result is very promising and suggests a potential of the cold spray method for the fusion applications.

Owing to the particle impingement principle, the surface of all coatings was relatively rough as compared to e.g., PVD or CVD processes. Their high specific surface area (in the as-sprayed condition) could potentially lead to unfavorable susceptibility to plasma particle erosion, triggering contamination of the plasma by the eroded tungsten content, yielding the coatings unsuitable for PFCs. However, this does not present a major problem as metallic cold sprayed coatings are easily machinable [60] by e.g., turning or milling. Thereby, the surfaces could be smoothed to a specified roughness without jeopardizing other coating properties.

In the literature, four sources pertaining to tungsten-based cold sprayed coatings can be found. In 2003, Kang and Kang [10] presented cold spraying of agglomerated (milled) W-25Cu composite powder. The starting feedstock $W$ particle sizes were very small, $\leq 1 \mu \mathrm{m}$, while the copper was $\leq 45 \mu \mathrm{m}$. The final powder was classified into $\leq 75 \mu \mathrm{m}$ range and preheated to $470{ }^{\circ} \mathrm{C}$ prior to spraying using nitrogen at $37.27 \mathrm{MPa}$ (this reported datum actually may be too high, a value of $3.727 \mathrm{MPa}$ would seem more probable at this state of CS technology development). The final coating thickness reached $600 \mu \mathrm{m}$ and the retained $\mathrm{W}$ content dropped to $37 \%$. This is significantly higher $\mathrm{W}$ phase loss than in our study, probably due to lower spray parameters used. Also, a formation of porosity was observed in their study, but the values remained fairly low, from $0.5-1.0 \%$. Understandably, the pores were mostly found around the W-rich regions in the coatings. Sixteen years later, the same materials combination was sprayed and its wear resistance was studied by Deng and co-workers [11]. In their study, three different 
W contents were used: 30,50, and 70\%. Again, these were formed using a very small W feedstock $(\leq 3 \mu \mathrm{m})$ and relatively big copper particles $(15-53 \mu \mathrm{m})$ blended together for $15 \mathrm{~h}$. Upon spraying with air at $500{ }^{\circ} \mathrm{C}$ at feedrates of $2.3-3.1 \mathrm{~kg} \cdot \mathrm{h}^{-1}$, the coatings exhibited declining thickness with increasing W content, reaching a total of $710 \mu \mathrm{m}, 220 \mu \mathrm{m}$, and $35 \mu \mathrm{m}$. Importantly, the thickness reduction was triggered even though the final $\mathrm{W}$ phase content in the coatings was dramatically reduced, yielding $12 \%$ and $19 \%$ of $\mathrm{W}$ only for the original $30 \%$ and $50 \% \mathrm{~W}$ powders. The $\mathrm{W}$ content for the coating from $70 \% \mathrm{~W}$ powder was not provided. Interestingly, there was a major disagreement between their study and the study of Kang and Kang [10]: while the former study suggested a decreasing 2-5\% porosity content with increasing $W$ content (explained by the tamping effect of non-bonded brittle W particles), Kang and Kang observed a completely inverse trend (explained by insufficient energy of incoming $\mathrm{W}$ particles). We speculate here that the difference could be caused by the different feedstock preparation routes (blend vs. agglomerated composite). Still, considering that the used spray parameters of the latter study are actually stronger, this interesting discrepancy well illustrates the somewhat uncomprehended nature of deposition of difficult-to-spray materials.

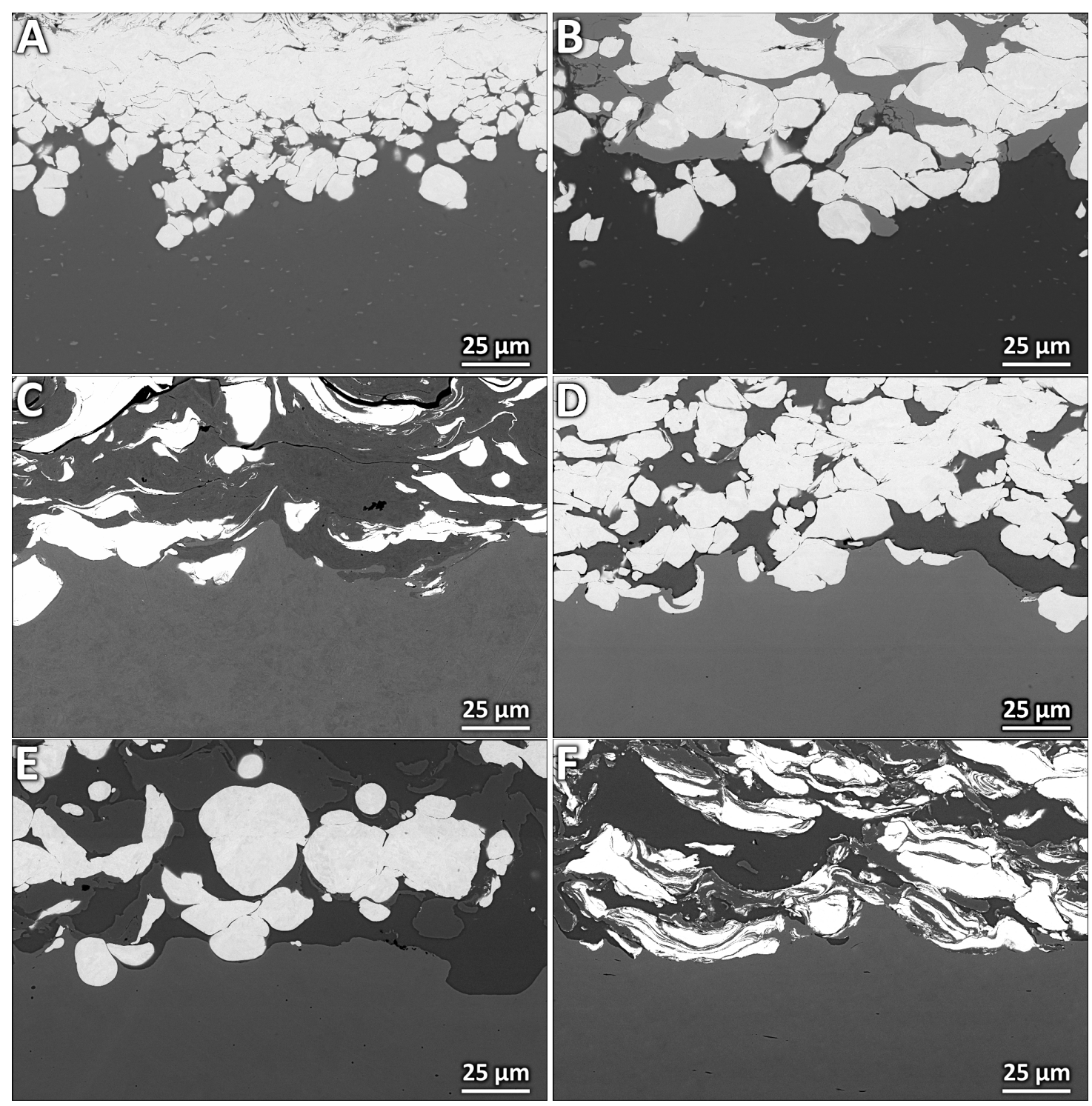

Figure 6. Interface of the produced cold spray coatings and underlying substrates. Al 6060 alloy was used for coatings A and B, relatively hard steel 1.1191 for coating C and medium hardness AISI 304 steel for coatings D-F. 
Another study performed by Barnett and colleagues [13] presented spraying of refractory mixtures to form donor tubes for explosive cladding. In their study, they used tantalum as the binder phase and a fairly low content of $\mathrm{W}(10 \%)$. Again, the tungsten powder was rather small $(5 \mu \mathrm{m}$, cf. the 10-15 $\mu \mathrm{m}$ and $\geq 20 \mu \mathrm{m}$ sizes of the $\mathrm{W}$ powders in our study), suggesting its better suitability for cold spraying at lower parameters. Using (expensive) helium at $400{ }^{\circ} \mathrm{C}$ and $2.5 \mathrm{MPa}$, they successfully managed to deposit coatings with thickness exceeding $1.5 \mathrm{~mm}$ (and subsequently remove the substrates by machining, thereby forming free-standing parts). Given the rather high content of the binder matrix, they reached deposition efficiencies as high as $85 \%$.

The study closest to ours in terms of W content was made by Xia and co-workers [12] in 2016. In their study, the binder matrix was a combination of nickel and iron at two different ratios: $17.5 \mathrm{Ni}$ $+7.5 \mathrm{Fe}$ and $4.9 \mathrm{Ni}+2.1 \mathrm{Fe}$ (yielding $75 \%$ and $93 \%$ of $\mathrm{W}$ in the feedstock, respectively). This time, the feedstock powders were all very small (3-10 $\mu \mathrm{m} \mathrm{W}, 2-5 \mu \mathrm{m} \mathrm{Ni}, 2 \mu \mathrm{m} \mathrm{Fe})$ and were co-milled for $12 \mathrm{~h}$. Prior to spraying, the powder was heated to $630^{\circ} \mathrm{C}$ to soften and then sprayed using air at $2.5 \mathrm{MPa}$. The $\mathrm{W}$ content in the final coatings ( $30 \%$ and $64 \%$ ) was comparable to the mixed feedstock results in our study and the porosities were rather low $(0.2-0.7 \%)$. The coating thickness reached up to $1.9 \mathrm{~mm}$ and the exhibited good adhesion ( $\geq 32 \mathrm{MPa}$ according to ASTM C-633 standard).

The elemental analysis and EDX mapping of our samples showed significant difference in the chemical composition of the coatings as compared to the starting feedstock. The difference in the $\mathrm{W} / \mathrm{Cr} / \mathrm{Ti}$ ratios is caused by a selective deposition of the individual constituents. This is, in turn, triggered by different densities of the three metals, their different particle sizes and morphologies, and also their individual crystallographic lattices (manifested in their deformability). The chromium levels in coatings B and C were $26 \%$ and $52 \%$, respectively. In combination with more deformed particles, the somewhat higher $\mathrm{Cr}$ content in the latter coating suggests more difficult $\mathrm{W}$ deposition from the process beginning that may be attributed to the harder steel substrate. In coating $D$, the initial $\mathrm{W} /$ Ti ratio of $95 / 5$ changed to $76 / 24$. This is, again, given by the selective deposition of the two constituents. Even though the higher Ti content does not present any major complication for the PFCs per se, a future experimental work is planned to reach a lower $\sim 10 \%$ Ti content in the final coatings. The composition of coatings $\mathrm{E}$ and $\mathrm{F}$ was very similar, with both retaining 45 and $51 \%$ of tungsten upon spraying, respectively. However, they differed slightly in the $\mathrm{Cr} / \mathrm{Ti}$ ratio $(28 / 27 \mathrm{vs} .18 / 31)$. This could be a consequence of the chromium content either inserted in its original pulverized form (i.e., relatively free of deformation) or in the form of a mechanically alloyed particles (i.e., with very high dislocation density and partially depleted of ductility).

Importantly, the coatings were not oxidized and retained metallic coloration. Upon a long-term EDX mapping, a slight oxygen content was observed to follow the $\mathrm{Cr}$ particles in the coating (absent for $\mathrm{W}$ and Ti particles). This is related to the same oxygen indication in the feedstock $\mathrm{Cr}$ powder, i.e., it is not attributed to the spray process. The absence of oxides is in accordance with the previous studies on CS deposition of $\mathrm{W}$ [10-13] and was further confirmed by the XRD process where the detected elements were confirmed as pure. The non-oxidized state is a prime advantage of the cold spray method over the other processes such as plasma spraying or HVOF, meeting the stringent criteria imposed by the fusion community on the armor coatings for the first wall in tokamaks.

The measured hardness of the coatings corresponded to their chemical composition (Table 1). The lowest hardness was recorded for the samples with the lowest W content (C, E). Similarly low content was recorded in the coating F. However, in this case, the pre-spray milling operation led to a significant increase in the hardness. The increase was caused by the increased dislocation density triggered by the cold working endured within the milling process. This suggests that the coating hardness can be increased by the feedstock milling; importantly, this can be achieved without compromising the tungsten component content (given the rather similar $\mathrm{W}$ levels in coatings $\mathrm{E}$ and $\mathrm{F}$ ). Naturally, the coatings with the high W content (A, D, B) exhibited highest hardness values (504 HV0.1, 444 HV0.3 and 410 HV0.3, respectively). Comparing the obtained results with the two studies that measured hardness of W-based cold sprayed coatings [11,12], one can see a trend of increasing hardness 
with increasing $\mathrm{W}$ content (Figure 7). Interestingly, this is somewhat irrespective of the binder matrix material $(\mathrm{Cu}$ [11], $\mathrm{Ni}+\mathrm{Fe}$ [12], $\mathrm{Cr}+\mathrm{Ti}$ in our study), suggesting a dominant role of $\mathrm{W}$ in this property. In accordance with our results, the coatings fabricated from milled feedstock in [11] reached higher hardness values.

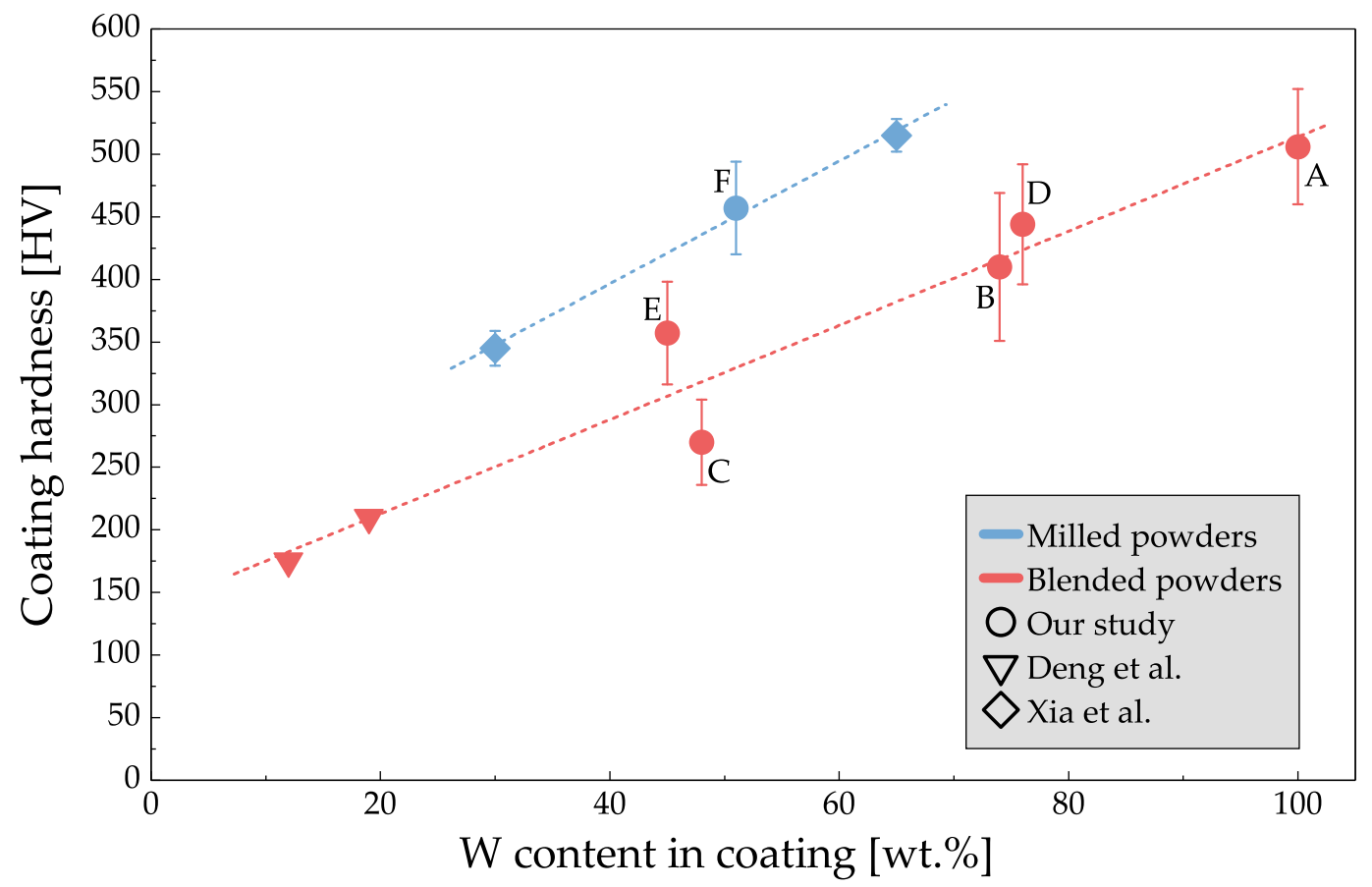

Figure 7. Hardness of the coatings from our study and two studies by Deng et al. [11] and Xia et al. [12]. There is a clear trend of increasing hardness with increasing W content (disregarding the different binder phases). The milled feedstock clearly reaches higher coating hardness values as opposed to the blended-only powders. The hardness in the graph is HV0.3 with the exception of the study [11] (HV0.05) and the coating with $100 \% \mathrm{~W}$ from our study (HV0.1).

The measured values of longitudinal $\left(\sim 4300 \mathrm{~m} \cdot \mathrm{s}^{-1}\right)$ and transversal $\left(\sim 2200 \mathrm{~m} \cdot \mathrm{s}^{-1}\right)$ waves propagation in the three Ti-containing coatings D-F (Table 2) are approximately $20 \%$ lower than those in pure polycrystalline bulk tungsten (indicated as $5220 \mathrm{~m} \cdot \mathrm{s}^{-1}$ and $2890 \mathrm{~m} \cdot \mathrm{s}^{-1}$ [61]). The waves propagation measurement allowed to determine the elastic constants of the three coatings. The density of the coating $\mathrm{D}$ was found to be higher, mostly because of the high $\mathrm{W}$ content (Table 2). The two coatings E, F differed only slightly as their chemical content was similar. Considering the theoretical moduli of the bulk W, Cr, and Ti (406 GPa, $248 \mathrm{GPa}$ and $120 \mathrm{GPa}$, respectively [61,62]) and the average composition of the coatings D-F, their theoretical average values should reach $392 \mathrm{GPa}$, $303 \mathrm{GPa}$, and $289 \mathrm{GPa}$. However, the measured moduli of the coatings are in general lower than these values, reaching $50-55 \%$ only (Table 2). Such reduced stiffness would suggest an imperfect bonding of the individual particles, potentially leading to elastic anisotropy in mechanical properties [63]. The determined waves propagation velocities of the three coatings are similar and do not exhibit any significant differences in either direction. That said, the differences in the elastic moduli of the three coatings are given by their different average densities rather than different mechanisms. 
Table 2. Elastic constants of the coatings D-F measured by through-transmission waves propagation method. Uncertainty levels resulting from the methodology are marked as "StDev". The relative moduli were calculated as the ratio of measured values to the theoretical prediction based on average elemental composition of the coatings.

\begin{tabular}{lccccc}
\hline Property & Unit & StDev & Coating \\
& & & E & F \\
\hline Density & $\mathrm{g} \cdot \mathrm{cm}^{-3}$ & 0.30 & 15.44 & 11.99 & 11.94 \\
Longitudinal waves velocity & $\mathrm{m} \cdot \mathrm{s}^{-1}$ & 80 & 4284 & 4377 & 4361 \\
Transversal waves velocity & $\mathrm{m} \cdot \mathrm{s}^{-1}$ & 80 & 2195 & 2297 & 2192 \\
Young's modulus & $\mathrm{GPa}$ & 10 & 197 & 166 & 153 \\
Relative modulus & $\%$ & - & 50 & 55 & 53 \\
Poisson number & - & 0.020 & 0.322 & 0.310 & 0.331 \\
\hline
\end{tabular}

A preliminary oxidation test was carried out to evaluate the potential of the coatings to mitigate formation of $\mathrm{WO}_{3}$, yielding them suitable as the armor coatings for the fusion application. Upon exposure to air at $1000{ }^{\circ} \mathrm{C}$ for $10 \mathrm{~h}$, the coatings D-F were completely oxidized. As expected, the coating $\mathrm{D}$ without chromium content prompted a severe oxidation of the tungsten, giving rise to formation of $78 \%$ of $\mathrm{WO}_{3}$ oxide and $22 \%$ of $\mathrm{TiO}_{2}$ (rutile). Given the expansion of $\mathrm{W}$ upon oxidation, such results would not be suitable for the application and could potentially jeopardize the integrity of the reactor. The two combinations with $\mathrm{Cr}$ content (E, F) showed an interesting (desired) potential to significantly suppress the $\mathrm{WO}_{3}$ formation, all the way to $38 \%$ and $34 \%$ content only, respectively. That said, the finer microstructure of the $\mathrm{W}$ and $\mathrm{Cr}$ particles in coating $\mathrm{F}$ brought only a slight improvement (a difference of $4 \%$ of $\mathrm{WO}_{3}$ as compared to the coating $\mathrm{E}$ from mixed-only feedstock). In both cases, the decrease was triggered by a formation of $\mathrm{Cr}_{2} \mathrm{WO}_{6}$ and $\mathrm{Cr}_{2} \mathrm{WO}_{3}$ chromium-tungstate oxides ( $9 \%$ and $8 \%$, respectively). Such complex oxides could be formed by a reaction of $\mathrm{WO}_{3}$ and $\mathrm{Cr}_{2} \mathrm{O}_{3}$. The latter actually forms a volatile $\mathrm{CrO}_{3}$ in the $1000-1200{ }^{\circ} \mathrm{C}$ region. As such, more detailed oxidation experiments are planned to understand the formation mechanisms, kinetics, and evaporation rates.

\section{Conclusions}

In our study, we presented a cold spray deposition of thick W and W-based coatings to be potentially used as a first wall armor in nuclear fusion. As opposed to other considered processes, the method presents a simple, one-step, commercially available technology capable of rapid covering of large-scale surfaces with coatings spanning hundreds of microns in thickness.

Owing to the observed good interface quality with the substrates, it should be trouble-free to securely and easily machine the coatings by turning or milling, without the requirement for any post-process technological steps. As we have shown, the materials are relatively hard, oxide-free and contain levels of tungsten that were never reached before (in fact, $100 \%$ pure $80 \mu \mathrm{m}$ tungsten coating was deposited for the first time). The coatings possess elastic moduli lower than bulks, and their densities (and chemical composition) can be fine-tuned by the feedstock selection. Importantly, their oxidation behavior improved by the addition of $\mathrm{Cr}$ content.

Combined, the cold spray technology holds a great potential for application in the nuclear fusion sector. Given the promising results, our ongoing research efforts are, at the moment, aimed at further improvement of the microstructure and properties of coatings with lower $\mathrm{Cr}$ contents as well as advanced oxidation tests of smooth, machined surfaces.

Author Contributions: conceptualization, J.C. and M.V.; methodology, J.C., M.V. and J.K.; software, J.K.; validation, J.C. and M.V.; investigation, J.C., M.V., F.L., M.K., J.K. and R.S.; resources, M.V., F.L., J.K. and R.S.; data curation, J.C., M.V. and F.L.; writing-original draft preparation, J.C. and M.V.; writing-review and editing, J.C., M.V., M.K. and R.S.; visualization, J.C.; project administration, J.C.; funding acquisition, M.V., F.L. and M.K.

Funding: This research was funded by Czech Science Foundation grants 17-23154S (M. Vilemova, F. Lukac) and 17-13573S (M. Koller). 
Conflicts of Interest: The authors declare no conflict of interest.

\section{References}

1. Matejicek, J. Materials for fusion Applications. Acta Polytech. 2013, 53, 197-212.

2. Pintsuk, G. Tungsten as a Plasma-Facing Material. In Comprehensive Nuclear Materials; Elsevier: Amsterdam, The Netherlands, 2012; Chapter 4.17, pp. 551-581.

3. Cizek, J.; Klecka, J. Harnessing fusion power: W and W-Cr armor coatings for plasma-facing components in tokamaks. Adv. Mater. Process. 2019, 177, 46-49.

4. Kikuchi, M.; Lackner, K.; Tran, M.Q. (Eds.) Fusion Physics; International Atomic Energy Agency: Vienna, Austria, 2012.

5. Litnovsky, A.; Wegener, T.; Klein, F.; Linsmeier, C.; Rasinski, M.; Kreter, A.; Unterberg, B.; Coenen, J.; $\mathrm{Du}, \mathrm{H}$.; Mayer, J.; et al. Smart tungsten alloys as a material for the first wall of a future fusion power plant. Nucl. Fusion 2017, 57, 066020. [CrossRef]

6. Lopez-Ruiz, P.; Ordas, N.; Iturriza, I.; Walter, M.; Gaganidze, E.; Lindig, S.; Koch, F.; Garcia-Rosales, C. Powder metallurgical processing of self-passivating tungsten alloys for fusion first wall application. J. Nucl. Mater. 2013, 442, S219-S224. [CrossRef]

7. Naidu, S.; Sriramamurthy, A.; Rao, P. The Cr-W (chromium-tungsten) system. Bull. Alloy Phase Diagrams 1984, 5, 289-292. [CrossRef]

8. Cizek, J.; Man, O.; Roupcova, P.; Loke, K.; Dlouhy, I. Oxidation performance of cold spray Ti-Al barrier coated gamma-TiAl intermetallic substrates. Surf. Coat. Technol. 2015, 268, 85-89. [CrossRef]

9. Cizek, J.; Matejkova, M.; Dlouhy, I.; Siska, F.; Kay, C.; Karthikeyan, J.; Kuroda, S.; Kovarik, O.; Siegl, J.; Loke, K.; et al. Influence of Cold Sprayed, Warm Sprayed and Plasma Sprayed Layers Deposition on Fatigue Properties of Steel Specimens. J. Therm. Spray Technol. 2015, 24, 758-768. [CrossRef]

10. Kang, H.; Kang, S. Tungsten/copper composite deposits produced by a cold spray. Scr. Mater. 2003, 49, 1169-1174. [CrossRef]

11. Deng, N.; Tang, J.; Xiong, T.; Li, J.; Zhou, Z. Fabrication and characterization of W-Cu composite coatings with different $W$ contents by cold spraying. Surf. Coat. Technol. 2019, 368, 8-14. [CrossRef]

12. Xia, M.; Huang, P.; Cu, R.; Ge, C. Cold sprayed W/Ni/Fe alloy coating: Microstructure and mechanical properties. Surf. Coat. Technol. 2016, 291, 376-381. [CrossRef]

13. Barnett, B.; Trexler, M.; Champagne, V. Cold sprayed refractory metals for chrome reduction in gun barrel liners. Int. J. Refract. Met. Hard Mater. 2015, 53, 139-143. [CrossRef]

14. Ji, G.; Wang, H.; Chen, X.; Bai, X.; Dong, Z.; Yang, F. Characterization of cold-sprayed multimodal WC-12Co coating. Surf. Coat. Technol. 2013, 235, 536-543. [CrossRef]

15. Ji, G.; Chen, X.; Wang, H.; Bai, X.; Dong, Z. Deformation Behaviors of Cold-Sprayed WC-Co Particles. J. Therm. Spray. Technol. 2015, 24, 1100-1110. [CrossRef]

16. da Silva, F.; Cinca, N.; Dosta, S.; Cano, I.; Couto, M.; Guilemany, J.; Benedetti, A. Corrosion behavior of WC-Co coatings deposited by cold gas spray onto AA 7075-T6. Corros. Sci. 2018, 136, 231-243. [CrossRef]

17. Kim, H.; Lee, C.; Hwang, S. Fabrication of WC-Co coatings by cold spray deposition. Surf. Coat. Technol. 2005, 191, 335-340. [CrossRef]

18. Kim, H.; Lee, C.; Hwang, S. Superhard nano WC-12\%Co coating by cold spray deposition. Mater. Sci. Eng. A 2005, 391, 243-248. [CrossRef]

19. Gao, P.; Li, C.; Yang, G.; Li, Y.; Li, C. Influence of substrate hardness on deposition behavior of single porous WC-12Co particle in cold spraying. Surf. Coat. Technol. 2008, 203, 384-390. [CrossRef]

20. Gao, P.; Li, Y.; Li, C.; Yang, G.; Li, C. Influence of Powder Porous Structure on the Deposition Behavior of Cold-Sprayed WC-12Co Coatings. J. Therm. Spray Technol. 2008, 17, 742-749. [CrossRef]

21. Gao, P.; Li, C.; Yang, G.; Li, Y.; Li, C. Influence of substrate hardness transition on built-up of nanostructured WC-12Co by cold spraying. Appl. Surf. Sci. 2010, 256, 2263-2268. [CrossRef]

22. Wang, H.; Chen, X.; Bai, X.; Ji, G.; Dong, Z.; Yi, D. Microstructure and properties of cold sprayed multimodal WC-17Co deposits. Int. J. Refract. Met. Hard Mater. 2014, 45, 196-203. [CrossRef]

23. Lima, R.; Karthikeyan, J.; Kay, C.; Lindemann, J.; Berndt, C. Microstructural characteristics of cold-sprayed nanostructured WC-Co coatings. Thin Solid Films 2002, 416, 129-135. [CrossRef] 
24. Couto, M.; Dosta, S.; Torrell, M.; Fernandez, J.; Guilemany, J. Cold spray deposition of WC-17 and 12 Co cermets onto aluminum. Surf. Coat. Technol. 2013, 235, 54-61. [CrossRef]

25. Couto, M.; Dosta, S.; Fernandez, J.; Guilemany, J.M. Comparison of the Mechanical and Electrochemical Properties of WC-25Co Coatings Obtained by High Velocity Oxy-Fuel and Cold Gas Spraying. J. Therm. Spray Technol. 2014, 23, 1251-1258. [CrossRef]

26. Couto, M.; Dosta, S.; Guilemany, J. Comparison of the mechanical and electrochemical properties of WC-17 and 12Co coatings onto Al7075-T6 obtained by high velocity oxy-fuel and cold gas spraying. Surf. Coat. Technol. 2015, 268, 180-189. [CrossRef]

27. Dosta, S.; Couto, M.; Guilemany, J. Cold spray deposition of a WC-25Co cermet onto Al7075-T6 and carbon steel substrates. Acta Mater. 2013, 61, 643-652. [CrossRef]

28. Dosta, S.; Bolelli, G.; Candeli, A.; Lusvarghi, L.; Cano, I.; Guilemany, J. Plastic deformation phenomena during cold spray impact of WC-Co particles onto metal substrates. Acta Mater. 2017, 124, 173-181. [CrossRef]

29. Ang, S.; Berndt, C.; Cheang, P. Deposition effects of WC particle size on cold sprayed WC-Co coatings. Surf. Coat. Technol. 2011, 205, 3260-3267. [CrossRef]

30. Li, C.; Yang, G.; Gao, P.; Ma, J.; Wang, Y.; Li, C. Characterization of Nanostructured WC-Co Deposited by Cold Spraying. J. Therm. Spray Technol. 2007, 16, 1011-1020. [CrossRef]

31. Yandouzi, M.; Sansoucy, E.; Ajdelsztajn, L.; Jodoin, B. WC-based cermet coatings produced by cold gas dynamic and pulsed gas dynamic spraying processes. Surf. Coat. Technol. 2007, 202, 382-390. [CrossRef]

32. Lioma, D.; Sacks, N.; Botef, I. Cold gas dynamic spraying of WC-Ni cemented carbide coatings. Int. J. Refract. Met. Hard Mater. 2015, 49, 365-373. [CrossRef]

33. Alidokht, S.; Manimunda, P.; Vo, P.; Yue, S.; Chromik, R. Cold spray deposition of a Ni-WC composite coating and its dry sliding wear behavior. Surf. Coat. Technol. 2016, 308, 424-434. [CrossRef]

34. Alidokht, S.; Vo, P.; Yue, S.; Chromik, R. Erosive wear behavior of Cold-Sprayed Ni-WC composite coating. Wear 2017, 376-377, 566-577. [CrossRef]

35. Alidokht, S.; Yue, S.; Chromik, R. Effect of WC morphology on dry sliding wear behavior of cold-sprayed Ni-WC composite coatings. Surf. Coat. Technol. 2019, 357, 849-863. [CrossRef]

36. Torgerson, T.; Harris, M.; Alidokht, S.; Scharf, T.; Aouadi, S.; Chromik, R.; Zabinski, J.; Voevodin, A. Room and elevated temperature sliding wear behavior of cold sprayed Ni-WC composite coatings. Surf. Coat. Technol. 2018, 350, 136-145. [CrossRef]

37. Nunthavarawong, P.; Sacks, N.; Botef, I. Effect of powder feed rate on the mechanical properties of WC-5 $\mathrm{wt} \% \mathrm{Ni}$ coatings deposited using low pressure cold spray. Int. J. Refract. Met. Hard Mater. 2016, 61, 230-237. [CrossRef]

38. Sacks, N. Low pressure cold gas dynamic spraying of tungsten carbide-nickel coatings. Met. Powder Rep. 2016, 71, 356-358. [CrossRef]

39. Melendez, N.; Narulkar, V.; Fisher, G.; McDonald, A. Effect of reinforcing particles on the wear rate of low-pressure cold-sprayed WC-based MMC coatings. Wear 2013, 306, 185-195. [CrossRef]

40. Melendez, N.; McDonald, A. Development of WC-based metal matrix composite coatings using low-pressure cold gas dynamic spraying. Surf. Coat. Technol. 2013, 214, 101-109. [CrossRef]

41. Lee, Y.; Ashrafizadeh, H.; Fisher, G.; McDonald, A. Effect of type of reinforcing particles on the deposition efficiency and wear resistance of low-pressure cold-sprayed metal matrix composite coatings. Surf. Coat. Technol. 2017, 324, 190-200. [CrossRef]

42. Yin, S.; Ekoi, E.; Lupton, T.; Dowling, D.; Lupoi, R. Cold spraying of WC-Co-Ni coatings using porous WC-17Co powders: Formation mechanism, microstructure characterization and tribological performance. Mater. Des. 2017, 126, 305-313. [CrossRef]

43. Peat, T.; Galloway, A.; Toumpis, A.; Steel, R.; Zhu, W.; Iqbal, N. Enhanced erosion performance of cold spray co-deposited AISI316 MMCs modified by friction stir processing. Mater. Des. 2017, 120, 22-35. [CrossRef]

44. Peat, T.; Galloway, A.; Toumpis, A.; McNutt, P.; Iqbal, N. The erosion performance of cold spray deposited metal matrix composite coatings with subsequent friction stir processing. Appl. Surf. Sci. 2017, 396, 1635-1648. [CrossRef]

45. Peat, T.; Galloway, A.; Toumpis, A.; McNutt, P.; Iqbal, N. The erosion performance of particle reinforced metal matrix composite coatings produced by co-deposition cold gas dynamic spraying. Appl. Surf. Sci. 2017, 396, 1623-1634. [CrossRef] 
46. Zhang, Y.; Epshteyn, Y.; Chromik, R. Dry sliding wear behaviour of cold-sprayed Cu-MoS2 and Cu-MoS2-WC composite coatings: The influence of WC. Tribol. Int. 2018, 123, 296-306. [CrossRef]

47. Zhang, Y.; Descartes, S.; Chromik, R. Influence of WC on third body behaviour during fretting of cold-sprayed Cu-MoS2-WC composites. Tribol. Int. 2019, 134, 15-25. [CrossRef]

48. Koller, M.; Seiner, H.; Landa, M.; Nieto, A.; Agarwal, A. Anisotropic elastic and acoustic properties of bulk graphene nanoplatelets consolidated by spark plasma Sintering. Acta Phys. Pol. A 2015, 128, 670-674. [CrossRef]

49. Sedlak, P.; Seiner, H.; Landa, M.; Novak, V.; Sittner, P.; Manosa, L. Elastic constants of bcc austenite and 2H orthorhombic martensite in CuAlNi shape memory alloy. Acta Mater. 2005, 53, 3643-3661. [CrossRef]

50. Hartsuijker, C.; Welleman, J. Engineering Mechanics: Stresses, Strains, Displacements; Springer: Berlin, Germany, 2007; Volume 2. [CrossRef]

51. Rietveld, H. Line profiles of neutron powder-diffraction peaks for structure refinement. Acta Cryst. 1967, 22, 151-152. [CrossRef]

52. Koivuluoto, H.; Vuoristo, P. Effect of powder type and composition on structure and mechanical properties of $\mathrm{Cu}+\mathrm{Al}_{2} \mathrm{O}_{3}$ coatings prepared by using low-pressure cold spray process. J. Therm. Spray Technol. 2010, 19, 1081-1092. [CrossRef]

53. Koivuluoto, H.; Bolelli, G.; Milanti, A.; Lusvarghi, L.; Vuoristo, P. Microstructural analysis of high-pressure cold-sprayed $\mathrm{Ni}, \mathrm{NiCu}$ and $\mathrm{NiCu}+\mathrm{Al}_{2} \mathrm{O}_{3}$ coatings. Surf. Coat. Technol. 2015, 268, 224-229. [CrossRef]

54. Lee, H.; Jung, S.; Lee, S.; You, Y.; Ko, K. Correlation between $\mathrm{Al}_{2} \mathrm{O}_{3}$ particles and interface of $\mathrm{Al}^{-} \mathrm{Al}_{2} \mathrm{O}_{3}$ coatings by cold spray. Appl. Surf. Sci. 2005, 252, 1891-1898. [CrossRef]

55. Xie, Y.; Yin, S.; Cizek, J.; Cupera, J.; Guo, E.; Lupoi, R. Formation mechanism and microstructure characterization of nickel-aluminum intertwining interface in cold spray. Surf. Coat. Technol. 2018, 337, 447-452. [CrossRef]

56. Walters, J.; Romero, J.; Mueller, A.; Stiteler, R.; Shah, H.; Oelrich, R. Thin cold sprayed coatings for nuclear fuel with enhanced accident tolerance. In Proceedings of the International Thermal Spray Conference, Yokohama, Japan, 26-29 May 2019; pp. 420-426.

57. Calvo, A.; Garcia-Rosales, C.; Koch, F.; Ordas, N.; Iturriza, I.; Greuner, H.; Pintsuk, G.; Sarbu, C. Manufacturing and testing of self-passivating tungsten alloys of different composition. Nucl. Mater. Energy 2016, 9, 422-429. [CrossRef]

58. Lessmann, M.; Sudic, I.; Fazinic, S.; Tadic, T.; Calvo, A.; Hardie, C.; Porton, M.; Garcia-Rosales, C.; Mummery, P. The effects of ion irradiation on the micromechanical fracture strength and hardness of a self-passivating tungsten alloy. J. Nucl. Mater. 2017, 486, 34-43. [CrossRef]

59. Vilemova, M.; Illkova, K.; Lukac, F.; Matejicek, J.; Klecka, J.; Leitner, J. Microstructure and phase stability of W-Cr alloy prepared by spark plasma sintering. Fusion Eng. Des. 2018, 127, 173-178. [CrossRef]

60. Yin, S.; Cizek, J.; Yan, X.; Lupoi, R. Annealing strategies for enhancing mechanical properties of additively manufactured 316L stainless steel deposited by cold spray. Surf. Coat. Technol. 2019, 370, 353-361. [CrossRef]

61. Lee, H.; Ando, S.; Coenen, J.; Mao, Y.; Riesch, J.; Gietl, H.; Kasada, R.; Hamaji, Y.; Ibano, K.; Ueda, Y. Longitudinal and shear wave velocities in pure tungsten and tungsten fiber-reinforced tungsten composites. Phys. Scr. 2017, T170, 014024. [CrossRef]

62. Mason, W. Acoustic properties of solids. In American Institute of Physics Handbook; McGraw-Hill: New York, NY, USA, 1972; Chapter 3f, pp. 98-117.

63. Seiner, H.; Cizek, J.; Sedlak, P.; Huang, R.; Cupera, J.; Dlouhy, I.; Landa, M. Elastic moduli and elastic anisotropy of cold sprayed metallic coatings. Surf. Coat. Technol. 2016, 291, 342-347. [CrossRef]

(C) 2019 by the authors. Licensee MDPI, Basel, Switzerland. This article is an open access article distributed under the terms and conditions of the Creative Commons Attribution (CC BY) license (http://creativecommons.org/licenses/by/4.0/). 